International Review of Research in Open and Distributed Learning Volume 19, Number 1

February - 2018

\title{
A Sharing Mind Map-oriented Approach to Enhance Collaborative Mobile Learning With Digital Archiving Systems
}

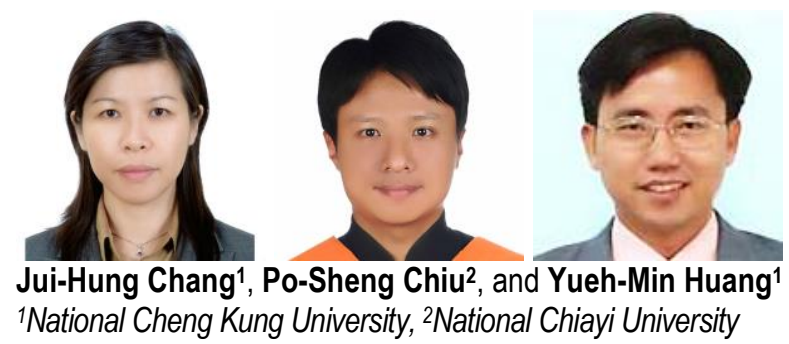

\section{Abstract}

With the advances in mobile network technology, the use of portable devices and mobile networks for learning is not limited by time and space. Such use, in combination with appropriate learning strategies, can achieve a better effect. Despite the effectiveness of mobile learning, students' learning direction, progress, and achievement may differ. Thus, the enhancement of learners' opinions on the usability and interactivity during mobile learning are challenging issues to overcome. This study developed a sharing mind map-oriented mobile learning system integrated with valuable information preserved in a digital archiving system. In addition to the functions of traditional mind maps, this system also enabled students to complete and record relevant information that they had found onto the mind map and further improve the integrity of their own knowledge. To investigate the effectiveness of this teaching approach, this study added digital archive data and used mind map sharing to help learners develop knowledge. By using the proposed approach, students were able to perform self-assessment on learning content, choose appropriate learning directions, and progress according to their level of learning. At the same time, they could collaboratively learn with peers to engage themselves more deeply in their learning. That is, their learning motivation could be constantly triggered through the observations and sharing of mind maps from one to another. This study selected sixth graders as its research subjects in two classes at the school where one researcher works. There were 31 and 30 valid samples in the experimental group and control group, respectively, with a total of 61 students. The experimental group was conducted by using sharing mind map with corresponding geographical archived information to investigate the effectiveness of sharing mind map (SMM) in mobile learning; on the other hand, the control group was conducted by using a traditional learning approach. The outcomes indicate that students' learning performance could be enhanced by using archived information SMM mobile learning.

Keywords: sharing mind map, collaborative mobile learning, digital archive, peer learning 


\section{Study Background}

In recent years, due to the process and enhancement of knowledge and science, e-learning management systems have increased rapidly. Many studies have pointed out that these techniques could optimize learning processes and effectiveness. Many scholars have utilized network technology for learning and statistical analysis, confirming the enhancement of the efficiency of learning by network technology. The development of mobile devices (e.g., smart phones, laptops, tablets, and so on) with wireless communication technology has changed the centuries-old rules for classroom instruction, resulting in breakthroughs in teaching methods (Biddix, Chung, \& Park, 2016). Due to the portable properties of mobile devices, mobile learning helps students to cooperate with others to improve their self-learning. Through mobile devices and wireless networks, e-learning can be conducted in informal learning contexts, such as outdoor teaching (Huang \& Chiu, 2015; Hwang, Wu, \& Ke, 2011; Park, Nam, \& Cha, 2012). Mobile learning can also make it possible to share knowledge quickly and help to enhance memorization.

Recently, content-aware environments, such as augmented reality and GPS positioning information, have been integrated into the learning process (Huang \& Chiu, 2015). However, because it is not location based, the learning effectiveness of mobile learning can only be assessed using various quantified reference values (e.g., number of hits, record of number of hours) of various learning behaviors. Students' actual perception of how effective their learning has been is usually ignored. In terms of the development of structured learning goals and objectives, it appears that students are not capable of planning learning progress by themselves. When students have to plan learning progress on their own or encounter learning obstacles, their progress tends to slow down and their learning effectiveness is affected. This situation can be resolved through the influence of peers, namely through collaborative learning (Chen \& Chang, 2016; DeWitt, Alias, \& Siraj, 2014). Eid and Al-Jabri (2016) investigated the relationship between sharing knowledge and independent learning in a college course. The results showed that the paired sharing mind model could benefit collaborative learning and learning activities, so as to enhance learning effectiveness. Sadeghi and Kardan (2016) suggested that computer supported technology can promote the potential of collaborative learning.

One way to examine how shared learning takes place in situations where it is difficult to infer the internal state of an individual within a group is when those individuals use graphic expression methods to interact with a collaborative and virtual learning environment using mobile devices. This makes it possible for every participant's interactions to be followed automatically. Zheng, Huang, Hwang, and Yang (2015) examined the degree of collaborative learning in a group by comparing the prior knowledge of group members before entering the group, and the knowledge demonstrated by the group after collaborating together. An analysis of the interactions between group members, and of the knowledge acquired, was undertaken by studying the group's computer-assisted knowledge maps. The results showed that scientific and technological tools brought about positive benefits to the enhancement of knowledge via collaborative learning. Contemporary students live in an era when information is expanding rapidly all around them. To make sense of all this information, they generally need some special methods, such as mnemonics, flow charts, and so forth. One of these special methods is the mind map (MM), which was first introduced by Buzan and Buzan (1996). Although the concept of the MM was not given much attention when it was first introduced, it has proven to have many advantages over other traditional methods for assisting 
learning. For instance, MM can effectively present information, which one hears or sees in a rich visual form, and MM can allow learners to use both of their left and right brains simultaneously, which can make it easier for learners to present their ideas. Liu, Zhao, Ma, and Bo (2014) summarized and integrated learning improvement related articles to understand learning efficiency via MM.. The results showed that MM could actually help improve learning. Moreover, numbers of studies showed that concept maps improved study quality in higher education. Radix and Abdool (2013) employed mind maps to facilitate creative learning tools. The actual collective creation with course mind maps in radiate structure could also effectively improve study quality.

\section{Motivation for the Study}

The introduction of mobile devices and digital archive resources changes the learning tool being used and adds additional content, which is an easy-to-achieve objective from the perspective of using technology (Johnston, Berg, Pillon, \& Williams, 2015). However, from the pedagogical perspective, what matters is whether this learning system can assist the learning process and improve the way learning takes place (Chiu \& Huang, 2015; Hwang et al., 2011). One way to make this assessment is to see if the use of a collaborative mobile learning system and the development of a collaboratively built digital archive can actually improve the quality of student learning (Ke \& Hsu, 2015). The purpose of this study was to design and use mind mapping and digital archiving as a tool for learners to self-construct their knowledge collaboratively and to see the degree to which this system helped learners expand their observations about the subject matter and interact with the learning environment. A key component of this system was its ability to make it possible for individual learners to observe their peers' working results when they were experiencing difficulties or were feeling unmotivated. The purpose was to motivate learners' interest by making it possible for them to improve or expand their own the mind maps by comparing them with their peers. During the process of sharing each other's mind maps, learners could understand how their peers presented different materials; then in turn, they could think through and expand their own perspectives. By using these techniques on their mobile devices, learners could reach their learning goals effectively without having to study in one geographic space.

\section{Research Questions}

In this study, an experiment was conducted by using shared mind maps with corresponding geographical archived information developed by the Taiwan e-Learning and Digital Archives Program (TELDAP) in order to investigate the effectiveness of sharing mind maps (SMM) in a mobile learning context. The following issues were thus explored:

1. When comparing the process of SMM in collaborative mobile learning and traditional learning, is SMM in collaborative mobile learning more effective than traditional learning?

2. In terms of the usability and interaction, is SMM in collaborative mobile learning more effective than traditional learning? 


\section{Literature Review}

\section{Digital Archives System (DAS)}

Digital archives are one of the main sources of digital learning materials (Frumkin, 2005; Johnston et al., 2015; Marchionini, Plaisant, \& Komlodi, 1998). Furthermore, Fuchs, Muscogiuri, Niederée, and Hemmje (2004) have suggested that digital archives can support digital learning since they collect and preserve information about human civilization over time, which provides teachers and students with valuable content to share and discuss together. In fact, many European countries have made great efforts to digitize their culture and history. These include the development of digitalized collections in the Vatican Museum, the Louvre Museum, the British National Gallery, the British Museum in London, and the British Library. Among them, the Vatican Museum has digitized valuable Vatican manuscripts to make them available for scholars all over the world to engage in historical study. The Louvre Museum has succeeded in digitalizing most of its collection with a special emphasis on multimedia technology. The British Museum selected specific collections for digitization focused on particular educational themes. In Taiwan, the National Science Council started to systemically sponsor a series of digital archive-related programs in 1998.

Johnston et al. (2015) defined digital archiving as the process where the collection of physical objects is converted into digital form, namely, the use of digitization technology to preserve physical objects or nonphysical objects which have value. To be more precise, the main objective of digital archives is to ensure that the digital data can be accessed, revised, and constantly archived. The actual contents of digital archives are collected, arranged, and organized using systemic and digitized approaches. During the process of digital archiving, metadata are essential construction elements. "Metadata" are used to define and divide electronic resources, as well as to assist in the accessibility of data (Chiu et al., 2016; DeRidder, 2007), enabling users or learners to easily look for the information they would like to learn about. Abundant and diversified contents in digital archives are excellent sources of teaching materials for teachers. The most appropriate teaching material resources can be assembled according to subject, field, and object. For learners, metadata are the best medium offering access to knowledge bases. With advanced mobile technology, if learners can use mobile devices to access relevant information collected as part of a field study, their learning interest and effectiveness can be enhanced.

\section{Sharing Mind Map (SMM)}

Buzan and Buzan (1996) came up with the idea of using graphs to improve people's ability to think. They called this assistive tool a mind map. A mind map is the use of images to present the thinking surrounding a central theme. Each idea is presented as a node on the graph, and can be linked to the sematic relations of other nodes. Owing to the linkages among sematic relations, each idea can be represented graphically and can be hyperlinked to webpages or other Internet resources. A mind map is composed of useful and organized ideas, can be very useful in decision-making, and can serve as a highly dynamic instrument for reorganizing ideas (Huang \& Chiu, 2015). In computer-supported cooperative work, a collaborative mind map can be used in the brainstorming activities of learners (Shih, Nguyen, Hirano, Redmiles, \& Hayes, 2009; Wilson, Copeland-Solas, \& Guthrie-Dixon, 2016). Recently, web technology-based mind map tools such as MindMeister and bubbl.us. have been developed. Shih et al. (2009) have proposed an experimental Group Mind system based on the improved collaborative software mind map proposed by 
FreeMind to explore the factors affecting the development of collaborative mind maps. Their experiment revealed that collaborative learning by using mind maps could achieve some advantages such as assisting teachers in fulfilling their duties, fully understanding and grasping students' ideas, and cultivating and organizing classes and groups.

\section{Collaborative Mobile Learning (CML)}

With the development of network technology, mobile learning or m-learning, is defined as the use of handheld devices in the classroom to connect with provided location-based content to achieve learning (Chiu \& Huang, 2015; Hwang et al., 2011). M-learning enables people to learn authentically through the local context. Thanks to mobile technology, learning resources become accessible and even exchangeable among learners through a portable device. For example, Wu, Hwang, Su, and Huang (2012) used mlearning and sensing technology to provide students with professional skills training, and enabled students to practice standard operating procedures through practice in actual field projects. Through data exchange using a mobile network, learners can overcome the limitations of time and space, interact with other peers, and further increase their learning interest and efficiency. On the one hand, learners can share learning information through the network. On the other hand, they can find peers with common interests by practicing communication and developing a population of correspondents for collaborative and cooperative learning. Formative assessment can also be used to establish an m-learning environment with enhanced effectiveness (Huang \& Chiu, 2015; Ryu \& Parsons, 2012; Valk, Rashid, \& Elder, 2010). To show the advantage of m-learning, Sandberg, Maris, and de Geus (2011) conducted an experiment which concluded that class learning could be taken to the next level by including field-based m-learning. Mobile environments appear to enhance collaborative learning. For instance, Huang, Jeng, and Huang (2009) depicted the development of an omnipresent learning environment via an annotation service, wireless telecom equipment, and jigsaw collaborative learning process. Through the statistics collected from the after-class survey, they showed that an annotation service provided by mobile equipment can aid in promoting students' learning potential. Mobile devices have become attractive devices in many aspects of education and learning. Many studies have focused on the value of mobile learning for students. Biddix et al. (2016) probed into the potential of mobiles devices in the professional development of teachers. It has become increasingly important for educational researchers to use qualitative and quantitative methods to examine the integration of mobile learning in education, and to examine its effectiveness on learning (Ke \& Hsu, 2015; Lee et al., 2016; Park, 2011; Hwang, \& Chang, 2016). The mobility afforded by electronic devices appears to be having a significant effect on students' ability to gain new knowledge, skills and experience.

\section{Sharing Mind Maps to Create Mobile Collaborative Learning}

In this study, a mobile collaborative learning environment was implemented to help learners construct their knowledge collaboratively through sharing mind maps. This study employed SMM for mobile collaborative learning, using digital archived information as the learning material for a local history course.

As shown in Figure 1, the sharing mind map mobile learning system mainly includes terminal learning components and server management components. Teachers and students can use different mobile devices (e.g., cellphones, PC, NB, and tablet PCs) to store data and use terminal learning components to engage in 
learning activities. They can also use mobile networks to store the data of digital archives and mind maps on the server.

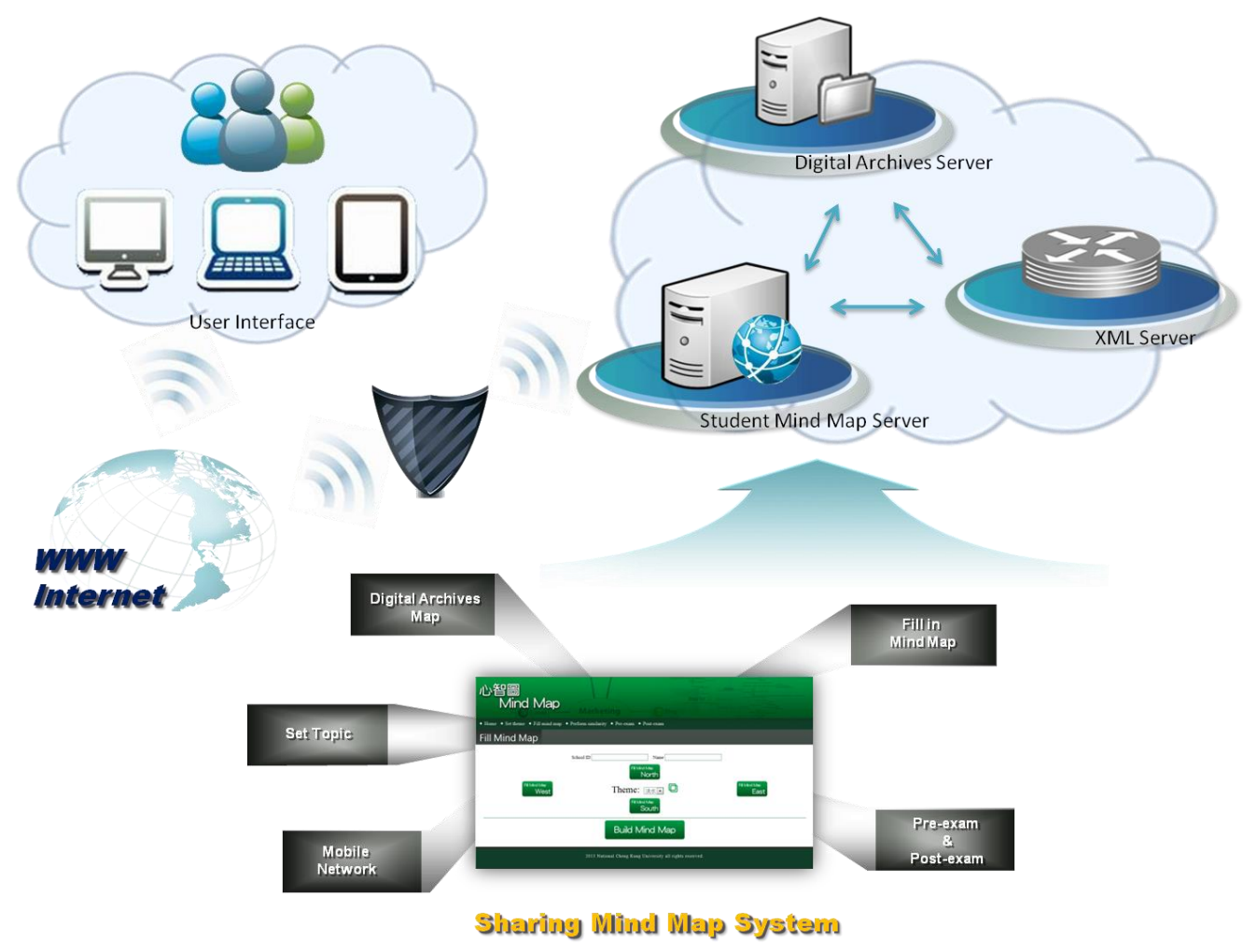

Figure 1. Architecture of the sharing mind map for mobile collaborative learning systems.

Sharing mind map system is written via HTML and JavaScript on mind map geography. The data are mainly saved as XML format. The XML file is shown as Appendix B. The framework is written based on PHP. The purpose of using these different languages is to enable the system to be used on diffetent platforms or any mobile devices to achieve mobile learning.

The modules provided by terminal learning components for teachers to use include a mind map theme setting module, a students' pre-and-post test score management module, and a digital archive information management module. In the mind map theme setting module, teachers can set up the learning theme according to the learning content to enable students to complete their mind maps based on that theme and through this process achieve learning effectiveness. In the students' pre-and-post test score management module, teachers can set up test questions in the server to pretest students' ability levels before they engage in learning activities. When the learning activities are concluded, post-tests of the experiment can be performed to assess how much students learned. This study intended to use preand-post test scores to verify whether the sharing mind system proposed in this study is feasible and effective for learning. In the digital archive information management module, teachers had to upload relevant learning materials into the digital archives for use in learning activities. When students are engaged in m-learning, searching for relevant keywords should automatically bring up relevant archived information for students to study (Figure 2). 


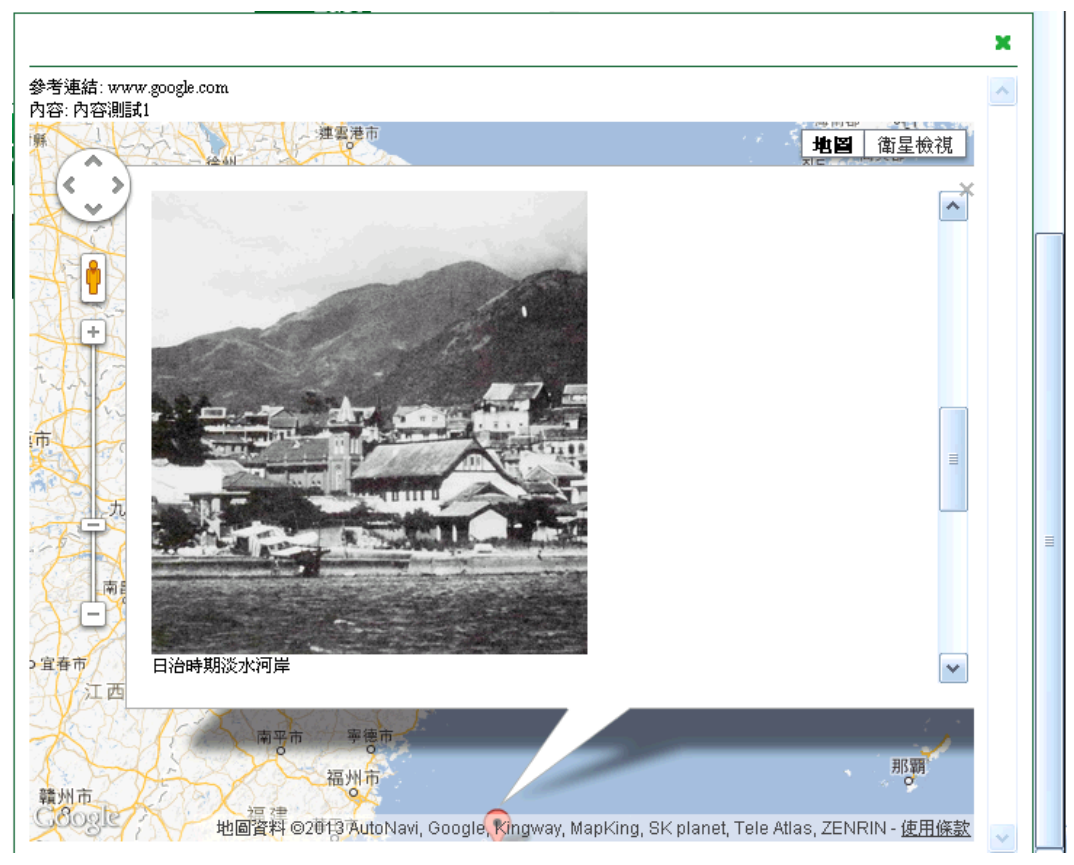

Figure 2. Digital archive information management module.

The learning mind map module. When students engage in thematic learning, they enter theme-related simple keywords in a diffusible form through the mind map. This helps them develop their overall thinking as well as their skills, because the mind map helps them develop their logic, organize ideas hierarchically, and construct images, which capture the relationship between ideas.

The pre-and-post experimental test module. During the experiment, students' performance on the pre-and-post experiment may vary. In that way, it is able to access whether the students have absorbed and understand the knowledge of the theme more quickly via sharing mind map.

The system questionnaire module. At the end of the overall learning experiment, the students in the experimental group and control group were asked to complete a system questionnaire to demonstrate their understanding of the usefulness, ease of use, interactivity of the system, and the users' acceptance for the system.

The community sharing mind map module. The mind map was used to set up a Facebook page to enable students to interact with teachers and classmates.

They could share their learning obstacles and achievements through communities and screen displays. (Figure 3) 


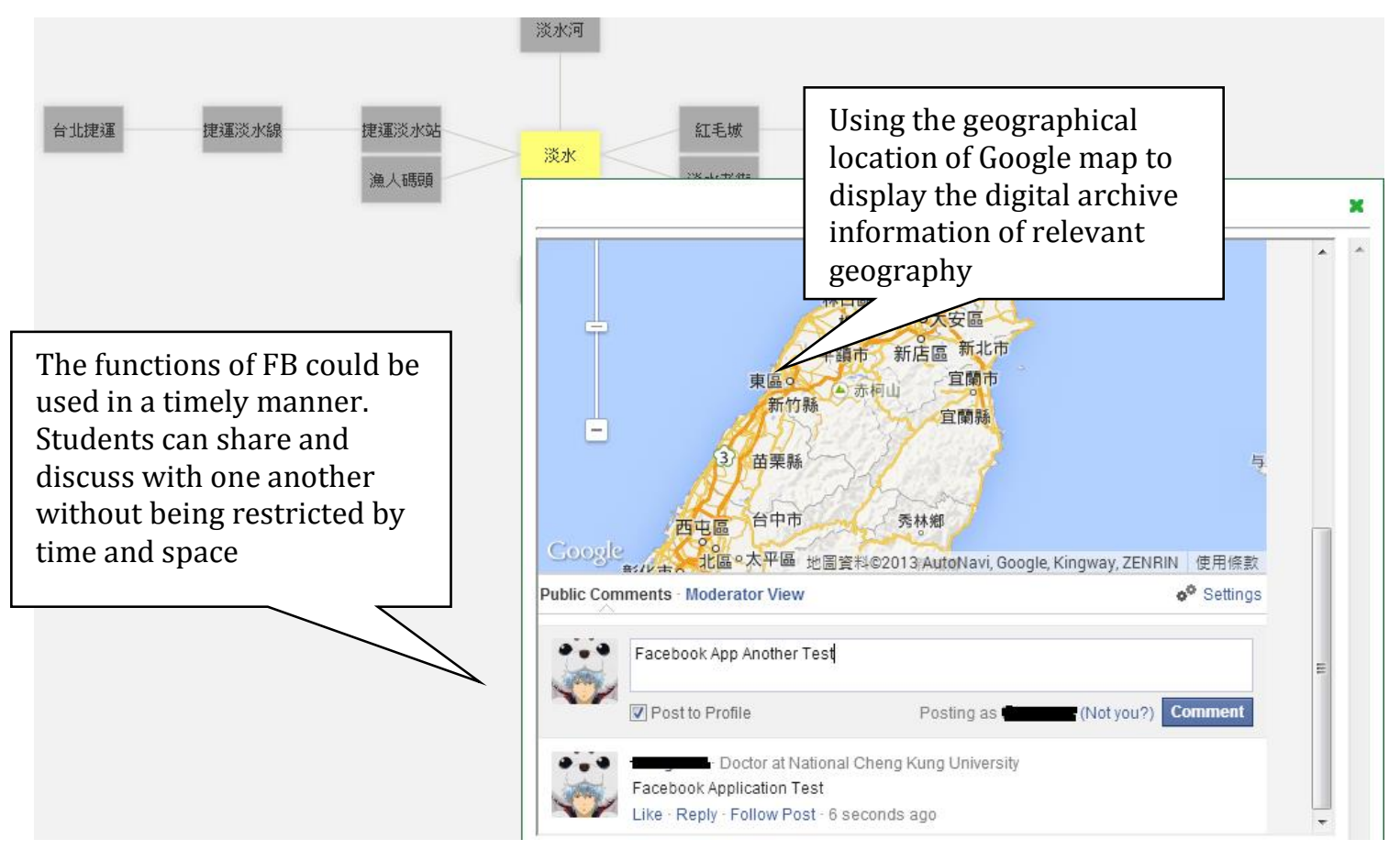

Figure 3. Community sharing mind map module.

\section{Research Design}

The learning activities were associated with geography and social studies in an elementary school, and were a part of the existing school courses. This study used mind maps and the digital archives information system to integrate relevant regional culture with history. Students' learning activities were composed of class teaching and outdoor field learning. During this study, the teacher could provide students with supplementary teaching materials in advance. Students could also add relevant information they found during the learning process.

\section{Participants}

The participants in the experiment were the sixth graders in two classes at the school where one of the researchers was a teacher. The students were divided into two groups. There were 31 valid samples in the experimental group, and there were 30 valid samples in the control group, with a total of 61 participants.

\section{Experimental Procedure}

First, the teacher established mind map-related themes in the system, and established the digital information of relevant themes in the system. The teacher set up the questions of the pre-and-post tests for the students in this system. The students were requested to undergo a pre-test before completing the mind map. This pre-test was intended to assess the students' degree of understanding of relevant themes before they were exposed to the information resources provided by this system. Afterwards, the students started to learn the digital information in the digital archive of the themes established by the teacher (as shown in Figure 4). In the example established in this study - the theme of "Danshui,"- students were shown scenes of Danshui in Japanese colonial times and screens of Danshui in the present time (as shown 
in Figure 5). The students could rapidly understand the track of historical changes in Danshui to deepen their understanding of how historical change took place.

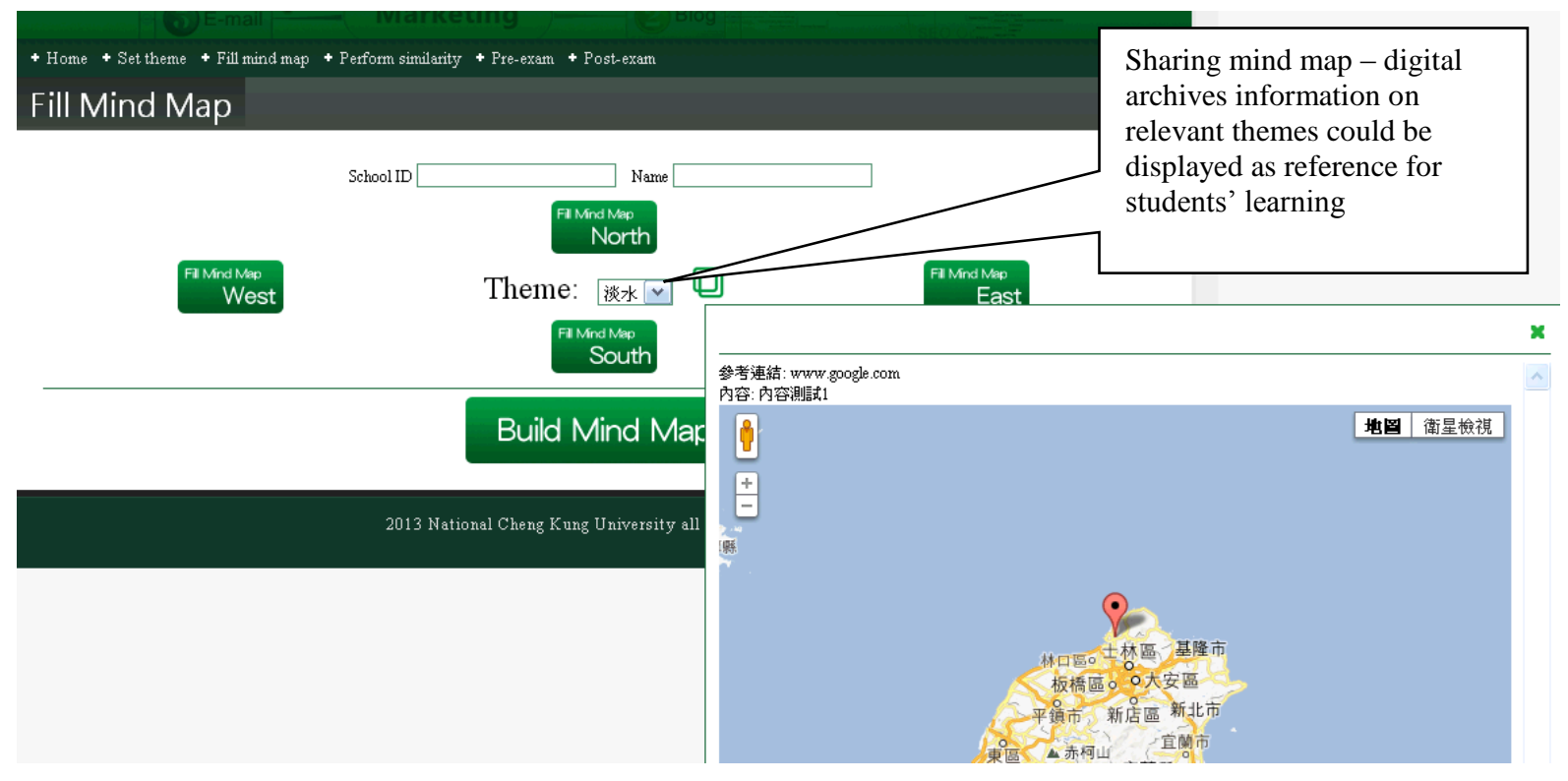

Figure 4. Digital archive map - Danshui. 


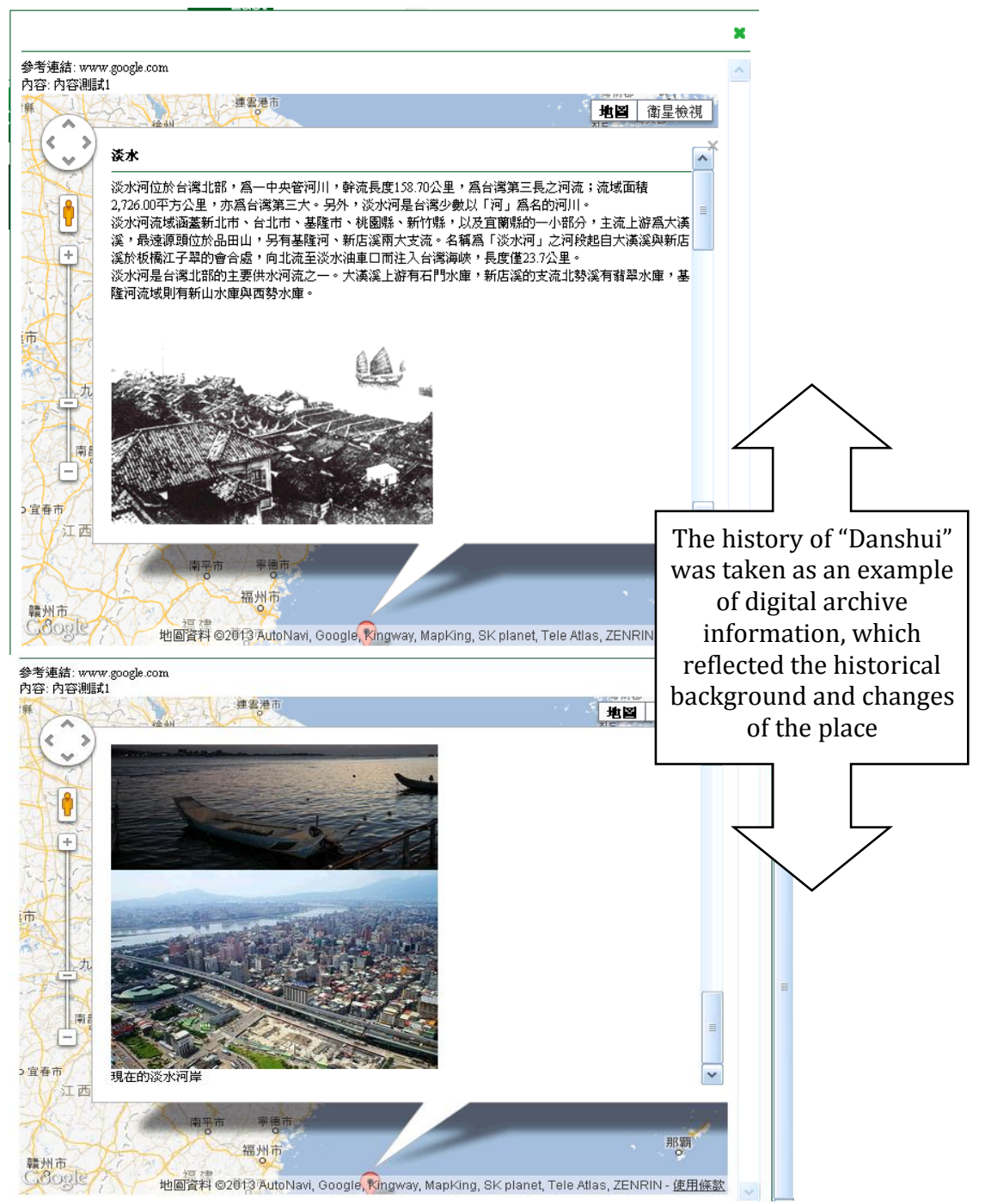

Figure 5. Digital archive map - Japanese colonial era and current status.

The students could complete the contents of a mind map after understanding the theme. In this assignment, in addition to filling in the traditional "keywords," the students could also fill in the site addresses they had researched, upload pictures, and fill in important content to enrich the information entered on the mind map. The developed mind map is shown in Figure 6. The keywords filled in by students could all automatically bring out relevant digital archive maps. The results could be provided for teachers to understand what content students had learned, as well as for peers' to observe and learn from. At the end of the course, the teacher performed a post-test to assess the degree to which the content knowledge of the students had increased between the student pre-tests and post-tests, as well as the benefits of such learning to students, after they had completed relevant mind maps and data searches. A detailed analysis of the experimental data are given in the following sections. 


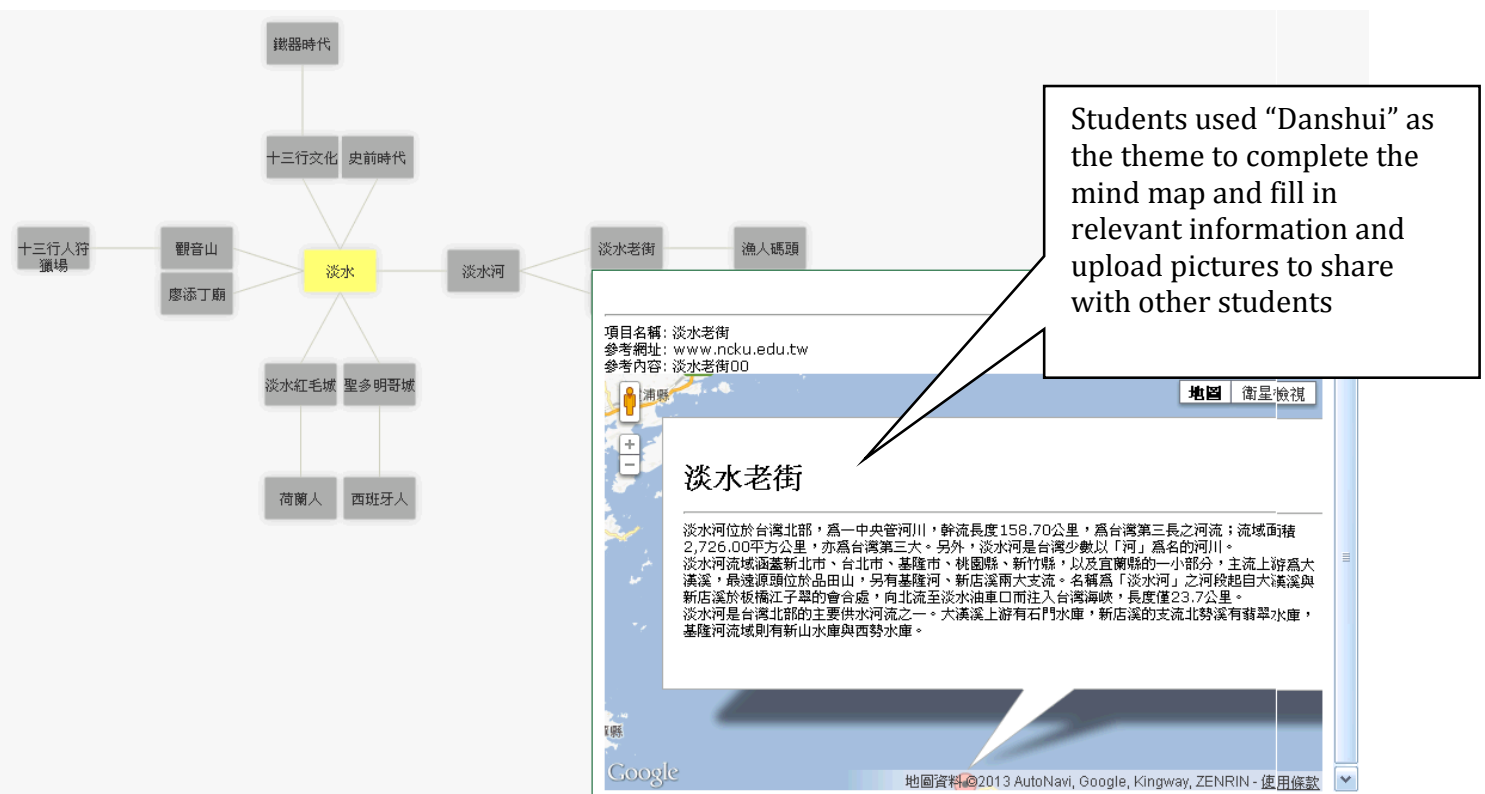

Figure 6. Development of the mind map.

This study used a mind map sharing system as the mind tool for learning. The students were assisted with their learning through observation and interaction in the learning environment. After the learners digested the knowledge they had learned in this study, their mind maps were further developed. Moreover, based on a comparison of similarities among the shared mind maps, the system further recommended mind maps with similar knowledge structures for learners to observe so that they could look at the learning achievements of other classmates. If users detected knowledge options that was different from what they had observed themselves, they could engage in self-learning and modify their own mind map structure.

This study focused primarily on differences in learning between two groups of learners using different learning approaches in the same learning environment. This study used the statistical method of dependent sample t-tests to test the two different kinds of mind maps developed by the learners and to analyze whether the sharing mind map system designed in this study improved the integrity of learners' knowledge structures.

Furthermore, this study used the mind map as a predictor variable, and used simple regression analysis to predict learners' perceived post-test scores. This study used statistical correlation analyses to perform its tests.

The experimental procedure of learning activities of the experimental and control group is shown in Figure 7 . 


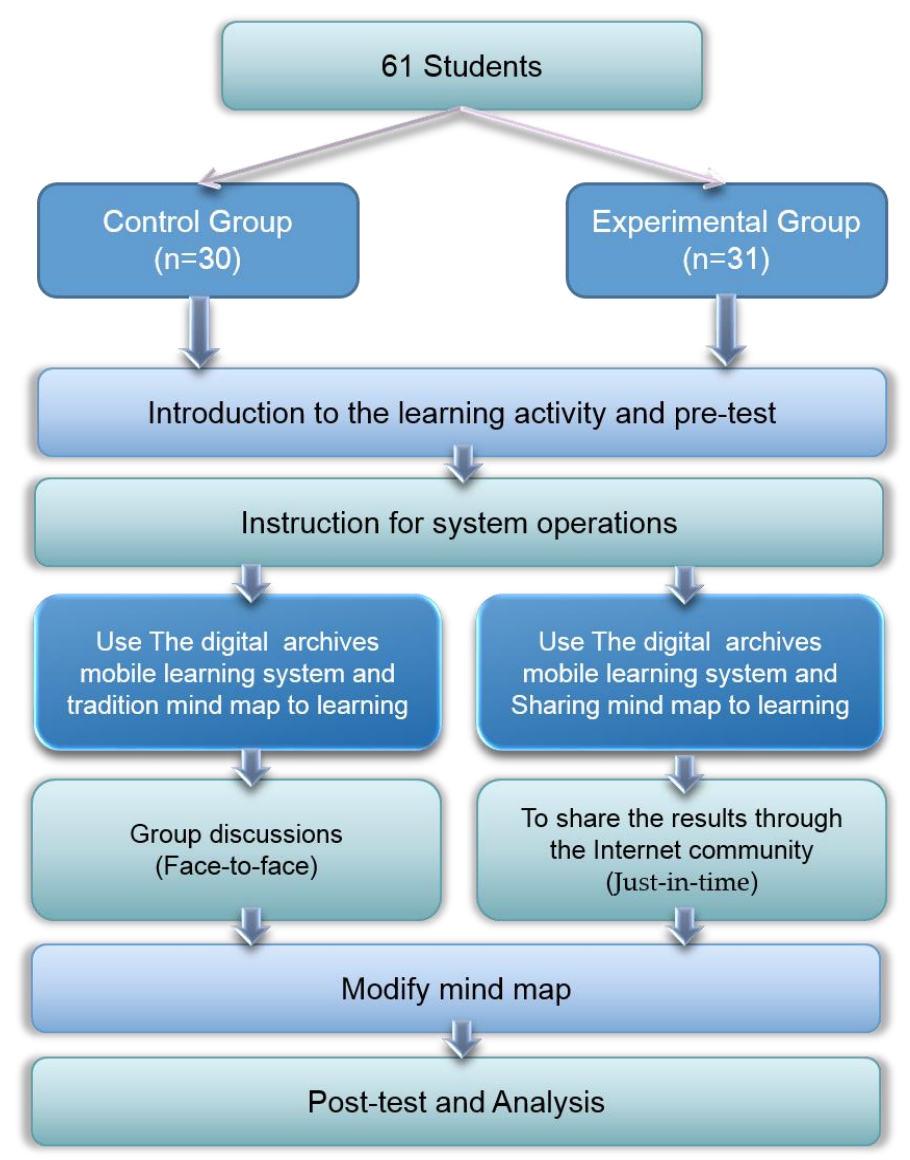

Figure 7. Experimental procedures.

This section investigated whether there was any difference in students' learning achievement in social studies after they participated in the teaching activities under different concept mapping models. This experiment selected the sixth graders in two classes as the subjects at the school where the researcher worked as a teacher. The subjects were divided into two groups. To conduct an objective study, the students in resources classes were excluded.

As shown in Figure 8, the students in the control group did not personally visit the place where resources are archived. Although the control group used the same mind tool of digitally archived resources, they did not use the function of internet community and could not discuss or share with other classmates instantly. Supplementary teaching material resources could be uploaded to mobile learning devices by scanning the QR code. At the end of the course, the teams shared and discussed with one another in a face-to-face manner. 


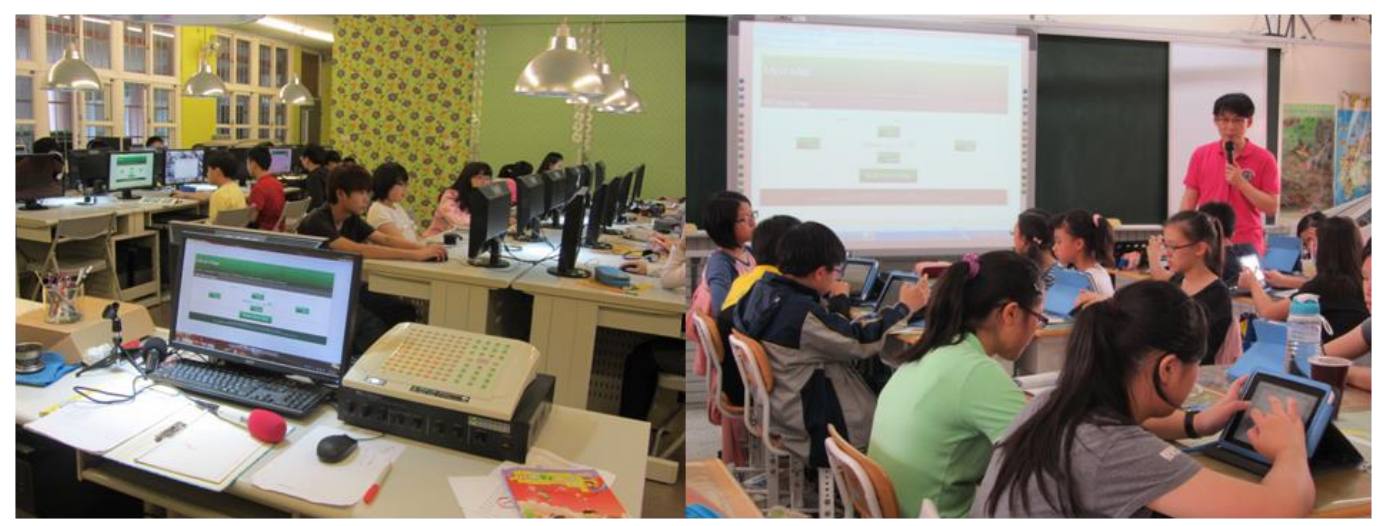

Figure 8. The learning activities of the control group.

As shown in Figure 9, the teacher led the students in the experimental group to the place where resources are archived to engage in SMM learning (The image is of Fort Santo Domingo). There was a built-in map of the route of the learning site in the mobile device that enabled students to look for the next place where resources were archived according to the images. Upon reaching the destination, the experimental group checked into places on Facebook. The system would instantly display the learning resources of the place to the experimental learning groups' mobile learning devices. In addition, they could use the internet community sharing mechanism to share with other teams. Other teams could engage in in-depth learning based on the information shared by the teams who had arrived earlier.

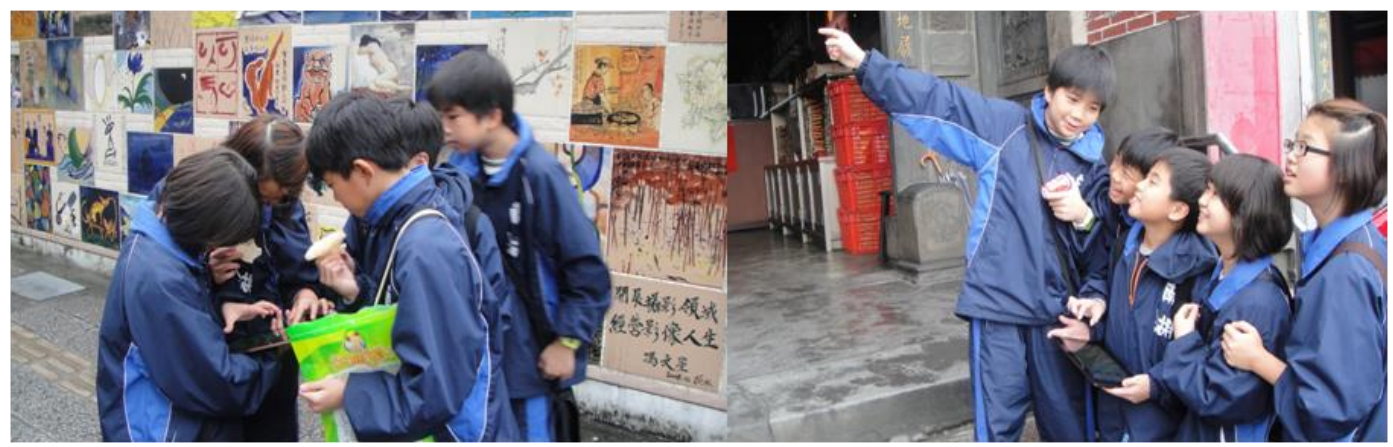

Figure 9. The learning activities of the experimental group.

There were 31 and 30 valid samples in the experimental group and control group, respectively, with a total of 61 subjects. The structured questionnaire used for assessment was developed according to formerly proposed digital archive systems. The students completed the questionnaire according to their level of agreement with the descriptions of questionnaire items. The levels of agreement were divided into 5 levels: (1) strongly disagree to (5) strongly agree. The result of the questionnaire is shown in Appendix A.

\section{Results and Discussions}

One of the aims of the study was to assess students' reactions to the mind map sharing model that they had been taught in this course. The following section presents an analysis of student responses to a 
questionnaire designed to make this assessment of student reactions. As shown in the Appendices, this questionnaire was divided into three dimensions, including questions relating to the usability of mind maps (11 items), the ease of use ( 3 items), and the interactivity ( 3 items), resulting in a total of 17 items. This study used independent sample t-tests as a statistical method with a confidence level of 95\%. A comparison of the two groups in terms of their response to using mind maps was as follows: The usability score of the experimental group was (Mean=44.29) higher than that of the control group (Mean=39.37), suggesting that satisfaction with the usability of the sharing mind map system was significantly greater than that of the traditional mind map system. In terms of ease of use, the score of the experimental group was (Mean=12.77) higher than that of the control group (Mean=12.17). In terms of interactivity, the score of the experimental group was (Mean=12.77) higher than that of the control group (Mean=12.17). The analyses and comparisons on the total scale and various dimensions are as follows (Table 1).

Table 1

T-Test Result of the Experimental Group/ Control Group

\begin{tabular}{llcccc}
\hline & Group & $\mathrm{N}$ & Mean & SD & t value \\
\hline Usability & Experimental group & 31 & 44.29 & $3.75^{2}$ & $5.71^{* * *}$ \\
\cline { 2 - 6 } & Control group & 30 & 39.37 & 2.918 & \\
\hline Ease of use & Experimental group & 31 & 12.77 & 1.309 & 1.86 \\
\cline { 2 - 6 } & Control group & 30 & 12.17 & 1.234 & \\
\hline Interactivity & Experimental group & 31 & 13.42 & 1.232 & $13.64^{* * *}$ \\
& & & & & \\
& Control group & 30 & 9.10 & 1.242 & \\
\hline
\end{tabular}

$* * * \mathrm{p}<.001$

Table1 focuses on students' acceptance of the sharing mind maps. The higher the score was, the more students accept the teaching approach, which indicates sharing mind map to be useful. A total of 11 questions are included. With a full score of 55, the average score of the experimental (44.29) was higher than the control group (39.37).

To test and analyze the difference in learning for the two groups due to different approaches in the learning environment, this study used paired sample t-tests. The statistical results are shown in Table 2: 
Table 2

Paired Sample Statistics

\begin{tabular}{|c|c|c|c|c|c|}
\hline & & Mean & $\mathrm{N}$ & SD & Significance \\
\hline \multirow{2}{*}{$\begin{array}{l}\text { Experimental } \\
\text { group }\end{array}$} & Pre-test & 67.48 & 31 & 12.720 & .000 \\
\hline & Post-test & 83.26 & 31 & 11.036 & \\
\hline
\end{tabular}

\begin{tabular}{llllll}
\hline Control group & Pre-test & 69.90 & 30 & 7.009 & .000 \\
& Post-test & 75.33 & 30 & 7.284 &
\end{tabular}

Within 95\% confidence interval of the experimental group and control group, both the upper bound and lower bound did not include o. The analysis for value of $\mathrm{p}$ was less than 0.001, showing significant difference in the average score of the two groups. This study used independent sample t-test to analyze the learning effectiveness of the experimental group and control group (as shown in Table 3).

Table 3

T-Test Result of the Pre-Test/Post-Test Scores

\begin{tabular}{llcccc}
\hline Variable & Group & $\mathrm{N}$ & Mean & SD & t value \\
\hline \multirow{2}{*}{ Pre-test } & Experimental group & 31 & 67.48 & 12.720 & -.92 \\
\cline { 2 - 6 } & Control group & 30 & 69.90 & 7.009 & \\
\hline \multirow{2}{*}{ Post-test } & Experimental group & 31 & 83.26 & 11.036 & $3.32^{* *}$ \\
\cline { 2 - 6 } & Control group & 30 & 75.33 & 7.284 & \\
\hline
\end{tabular}

** $\mathrm{p}<.01$

The statistical analysis found that the average post-test score of the experimental group was 83.26 points, while that of the control group was 75.33 points. The results showed that there was a significant difference in the total scale scores relating to the acceptance of mind maps between the two groups $(\mathrm{t}=3.32, \mathrm{p}=.002$ $<.01)$. The comparison of the learning performance of the concept mapping of the two groups showed that the learning performance of the experimental group was better, and the difference between the experimental group and control group reached a level of significance. Based on these analyses, the results showed that the overall acceptance of the group receiving the sharing mind map-assisted teaching was 
higher than that of the group receiving the traditional mind map-assisted teaching. In addition, the difference reached a level significance. Moreover, compared with the traditional learning approach the learning effectiveness of sharing mind maps was better. According to an analysis of the responses to questions about the usage of digital archive resources during the experiment and following a review of the qualitative data of interviews with teachers and some of the students, this study has also attempted to define the way in which the introduction of digital archive resources to SMM influenced teachers' instruction.

The introduction of the SMM of digital archive resources to the teaching of social studies can enrich learners' knowledge and enhance their interest in mapping, which can then enhance their knowledge network. The introduction of SMM archive resources helps improve the problem-solving ability and attitude of teachers and learners. Such an interactive model can also improve teaching atmosphere. The teacher in this study suggested that the concept of digital archives in Taiwan still needs to be further developed. Existing comparisons of the development of foreign and domestic digital archives show that digital archives have attracted global attention. However, it is difficult to retrieve data from most of the teaching resource websites. It is easy to look for texts. However, it is difficult to look for multimedia data, such as images and videos. Good resource websites provide detailed classification and diversified data that are convenient to search. However, the content of poorly designed websites is scattered and cannot be easily retrieved. For effective data retrieval it is necessary and imperative to develop complete plans and technology for the retrieval of metadata. The TELDAP portal integrates many advantageous features. Therefore, this study introduced the resources of TELDAP to SMM to assist learners in developing their own knowledge networks. The TELDAP portal made it possible for learners to comprehensively obtain theme-related data and to explore topics in-depth. It also helped to trigger their learning interest, improve their learning attitude and willingness, and develop habits of spontaneous and comprehensive learning.

This paper has reported the results of an investigation into the introduction of digital archives to SMM and their advantages and disadvantages. These results are summarized as follows:

\section{Advantages}

- Proves to be useful, and supports persistence, interactivity, instant discussion, intelligent integration, and also provides users with the capability of permanently and properly storing data.

- Users are able to conveniently, rapidly, and accurately find the information they need.

- Provides free and high quality images without copyright concerns that can be freely used for teaching and commercial purposes.

\section{Disadvantages}

- The authenticity of some of the introduced archive resources of SMM is not high enough.

- Some of the collections introduced from archive resources of SMM are missing and are not reliable. Some of the digital archive resources where copyright acquisition is required are not fully available for retrieval, leading to incomplete data display on mind maps. 
- The documentation of the history or origin of photographs of some of the introduced SMM archive resources are unclear.

- There are no user instructions or tips on the homepage of the SMM interface relating to introduced digital archive resources.

Learners' opinions on the usability, ease of use, and interactivity of the digital archive resources introduced in this study. According to the interviews with the subjects concerning the introduction of the SMM system of archive resources proposed in this study, the subjects suggested that they were highly interested in the integration of network communities using the mind map tool. In this digital era, almost every person has used social networks. Presumably, this makes it easy to use SMM. In addition, the subjects in the experimental group and control group indicated that they had used mind map tool Xmind in other courses. Therefore, they were familiar with drawing mind maps. However, they were still confused in the beginning when using the SMM where the two functions were integrated.

The operating interface of the SMM proposed in this study was different from the subjects' past experience using mind map tools. Since the subjects were younger, they encountered a few obstacles during the development of mind maps. In addition, there were no user instructions and interactive tips on the user interface. Therefore, before detailed explanations had been given, most of the subjects encountered setbacks when interacting with the interface. However, after trying several times, they gradually got used to the interface when using it to engage in instant sharing and interacting with the social network. Although teachers in some classes earnestly prepare teaching materials, the quality of some of the images they find online is inconsistent and images cannot be zoomed in on for the close observation of details. Fortunately the subjects in this study found that most of the images displayed in the SMM digital archive resources were high-resolution. After the class, the subjects indicated that the instant sharing mechanism of SMM enhanced their afterschool desire for knowledge. They became interested in looking for new tools or new perspectives to share with other subjects. SMM also increased parent-child interaction. Some students indicated that they would discuss what they were involved in with their parents and looked for answers together. They would even look for other mind map tools or apps for comparison and sharing.

It is apparent that this experiment enabled students to apply the concept of instant sharing to their learning mind map development process by involving themselves in a network community and by introducing digital archive resources. Based on the teachers' and students' user experience mentioned above, this study found that there will be an adaptation period for users to become familiar with the new technology. If user instructions or interactive tips can be added to the homepage for first-time users, they can use the system more easily and intuitively and will be able to smoothly edit, revise, and display their concept maps. This would help learners apply the SMM tool with ease and flexibly. 


\section{Conclusion}

This study designed a sharing mind map system integrated with valuable digital information preserved in digital archives. In addition to the functions of traditional mind maps, this system also enabled students to complete and record relevant information, which they had found on the mind map, to further improve the integrity of their own knowledge. In order to investigate the effectiveness of this teaching approach, this study added digital archive data and used mind map sharing as a way to help learners develop knowledge. The results of the experiment showed that, compared to general digital archive resource learning systems, the learning effectiveness of this teaching approach was better. Moreover, according to the assessment of outside experts, the integrity of the learners' knowledge structure was indeed improved after they participated in this method of learning.

Although the sharing mobile mind map teaching approach proposed in this study verified the advantages of this system, two problems still have to be solved in future studies. One problem includes the exploration into the influence of cognitive style on learners. The site-dependent or site-independent nature of learners themselves will affect their learning effectiveness regardless of whether the sharing mobile mind map or the general digital archive learning approach is used. The second problem requiring exploration includes a look into the influence on elementary school students' perceived ease of use. This study did not investigate the influence of perceived usability and perceived ease of use on learning attitude. Future studies should develop experiments to investigate these issues.

\section{References}

Biddix, J. P., Chung, C. J., \& Park, H. W. (2016). Faculty use and perception of mobile information and communication technology (m-ICT) for teaching practices. Innovations in Education and Teaching International, 53(4), 375-387. doi: 10.1080/14703297.2014.997778

Buzan, T., \& Buzan, B. (1996). The mind map book: How to use radiant thinking to maximize your brain's untapped potential. Penguin Publishing Group.

Chen, S. Y., \& Chang, L.-P. (2016). The influences of cognitive styles on individual learning and collaborative learning. Innovations in Education and Teaching International, 53(4), 458-471. doi: 10.1080/14703297.2014.931242 
Chiu, P.-S., Chao, I.-C., Kao, C.-C., Pu, Y.-H., Huang, Y.-M., Seadle, M., \& Schilow, L. (2016). Implementation and evaluation of mobile e-books in a cloud bookcase using the information system success model. Library Hi Tech, 34(2).

Chiu, P.-S., \& Huang, Y.-M. (2015). The development of a decision support system for mobile learning: a case study in Taiwan. Innovations in Education and Teaching International, 1-13. doi: 10.1080/14703297.2015.1020328

DeRidder, J. L. (2007). Choosing software for a digital library. Library Hi Tech News, 24(9/10), 19-21. doi: doi:10.1108/07419050710874223

DeWitt, D., Alias, N., \& Siraj, S. (2014). The design and development of a Collaborative mLearning prototype for Malaysian secondary school science. Etr\&D-Educational Technology Research and Development, 62(4), 461-480. doi: 10.1007/s11423-014-9340-y

Eid, M. I. M., \& Al-Jabri, I. M. (2016). Social networking, knowledge sharing, and student learning: The case of university students. Computers \& Education, 99, 14-27. doi: 10.1016/j.compedu.2016.04.007

Frumkin, J. (2005). The wiki and the digital library. OCLC Systems \& Services: International digital library perspectives, 21(1), 18-22.

Fuchs, M., Muscogiuri, C., Niederée, C., \& Hemmje, M. (2004). Digital libraries in knowledge management: An e-learning case study. International Journal on Digital Libraries, 4(1), 31-35.

Huang, Y.-M., \& Chiu, P.-S. (2015). The effectiveness of the meaningful learning-based evaluation for different achieving students in a ubiquitous learning context. Computers \& Education, 87, 243253 .

Huang, Y.-M., Jeng, Y.-L., \& Huang, T.-C. (2009). An educational mobile blogging system for supporting collaborative learning. Educational Technology \& Society, 12(2), 163-175.

Huang, Y. M., \& Chiu, P. S. (2015). The effectiveness of a meaningful learning-based evaluation model for context-aware mobile learning. British Journal of Educational Technology, 46(2), 437-447.

Hwang, G.-J., Wu, P.-H., \& Ke, H.-R. (2011). An interactive concept map approach to supporting mobile learning activities for natural science courses. Computers \& Education, 57(4), 2272-2280. doi: http://dx.doi.org/10.1016/j.compedu.2011.06.011

Johnston, D. J., Berg, S. A., Pillon, K., \& Williams, M. (2015). Ease of use and usefulness as measures of student experience in a multi-platform e-textbook pilot. Library Hi Tech, 33(1), 65-82.

Ke, F., \& Hsu, Y.-C. (2015). Mobile augmented-reality artifact creation as a component of mobile computer-supported collaborative learning. The Internet and Higher Education, 26, 33-41. 
Lee, H., Parsons, D., Kwon, G., Kim, J., Petrova, K., Jeong, E., \& Ryu, H. (2016). Cooperation begins: Encouraging critical thinking skills through cooperative reciprocity using a mobile learning game. Computers \& Education, 97, 97-115.

Liu, Y., Zhao, G., Ma, G., \& Bo, Y. (2014). The effect of mind mapping on teaching and learning: A metaanalysis. Standard Journal of Education and Essay, 2(1), 17-31.

Marchionini, G., Plaisant, C., \& Komlodi, A. (1998). Interfaces and tools for the Library of Congress national digital library program. Information processing \& management, 34(5), 535-555.

Park, S. Y., Nam, M. W., \& Cha, S. B. (2012). University students' behavioral intention to use mobile learning: Evaluating the technology acceptance model. British Journal of Educational Technology, 43(4), 592-605.

Park, Y. (2011). A pedagogical framework for mobile learning: Categorizing educational applications of mobile technologies into four types. International Review of Research in Open and Distance Learning, 12(2), 78-102.

Radix, C.-A., \& Abdool, A. (2013). Using mind maps for the measurement and improvement of learning quality. The Caribbean Teaching Scholar, 3(1).

Ryu, H., \& Parsons, D. (2012). Risky business or sharing the load?-Social flow in collaborative mobile learning. Computers \& Education, 58(2), 707-720.

Sadeghi, H., \& Kardan, A. A. (2016). Toward effective group formation in computer-supported collaborative learning. Interactive Learning Environments, 24(3), 382-395. doi: 10.1080/10494820.2013.851090

Sandberg, J., Maris, M., \& de Geus, K. (2011). Mobile English learning: An evidence-based study with fifth graders. Computers \& Education, 57(1), 1334-1347.

Shih, P. C., Nguyen, D. H., Hirano, S. H., Redmiles, D. F., \& Hayes, G. R. (2009). GroupMind: supporting idea generation through a collaborative mind-mapping tool. Paper presented at the Proceedings of the ACM 2009 international conference on Supporting group work, Sanibel Island, Florida, USA.

Sung, H.-Y., Hwang, G.-J., \& Chang, Y.-C. (2016). Development of a mobile learning system based on a collaborative problem-posing strategy. Interactive Learning Environments, 24(3), 456-471.

Wilson, K., Copeland-Solas, E., \& Guthrie-Dixon, N. (2016). A preliminary study on the use of mind mapping as a visual-learning strategy in general education science classes for arabic speakers in the United Arab Emirates. Journal of the Scholarship of Teaching and Learning, 16(1), 31-52. 
Wu, P.-H., Hwang, G.-J., Su, L.-H., \& Huang, Y.-M. (2012). A context-aware mobile learning system for supporting cognitive apprenticeships in nursing skills training. Educational Technology \& Society, 15(1), 223-236.

Valk, J.-H., Rashid, A. T., \& Elder, L. (2010). Using mobile phones to improve educational outcomes: An analysis of evidence from Asia. International Review of Research in Open and Distance Learning, 11(1), 117-140.

Zheng, L., Huang, R., Hwang, G.-J., \& Yang, K. (2015). Measuring knowledge elaboration based on a computer-assisted knowledge map analytical approach to collaborative learning. Educational Technology \& Society, 18(1), 321-336. 


\section{Appendix A}

\section{The Questionnaire Model}

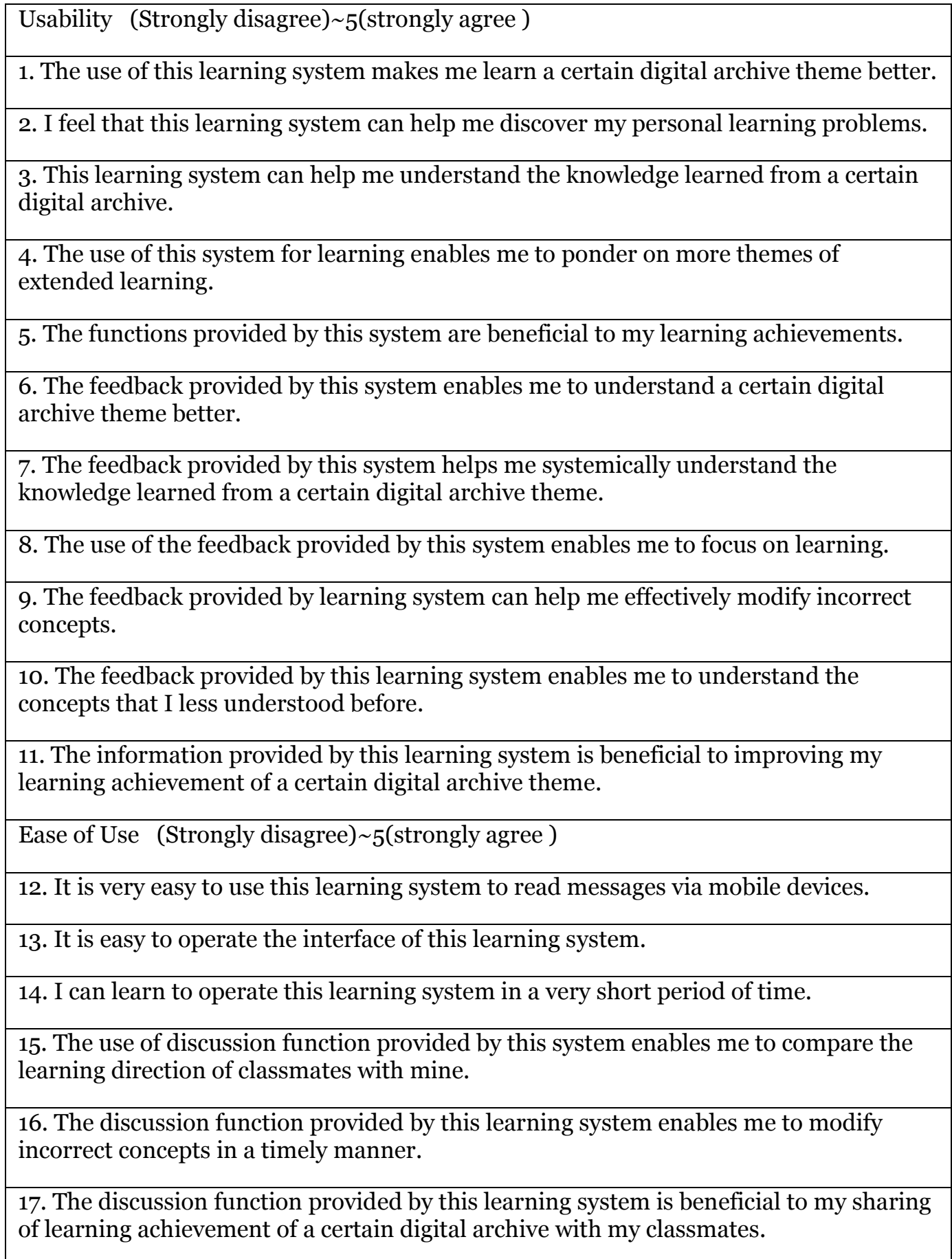

${ }^{*}$ Note. The levels of agreement were divided into 5 levels: (1) strongly disagree; (5) strongly agree. 


\section{Appendix B}

\section{Mind Map XML Format}

Mind map XML format requires theme code, student id number, and the location to make the file name. The file content needs to include a student id number (school_id), name (full_name), and the theme (theme). Every child filled in by the students includes an id, name, and data. The related data are the url and the content. Every child might have more sub-children.

ex:

$<$ ?xml version="1.0" encoding="utf-8"?>

$<$ content $>$

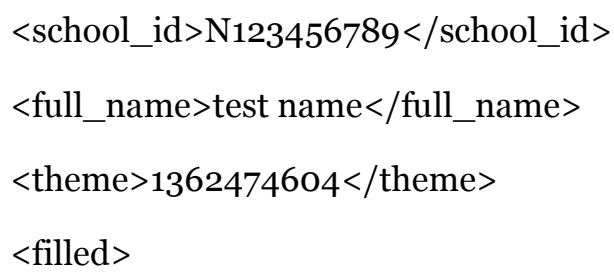


$<$ id $>$ 39739a52e1f28be8f8329771b6c4bo6b $</$ id $>$

$<$ name $>$ Tamsui [Danshui] Old Street $<$ /name $>$

$<$ data $>$

<url >www.google.com.tw</url>

$<$ content $>$ test $3<$ content $>$

$<$ data $>$

$<$ children $><$ /children $>$

$</$ children $>$

$</$ filled $>$

$</$ content $>$

\section{Mind Map System is Output}

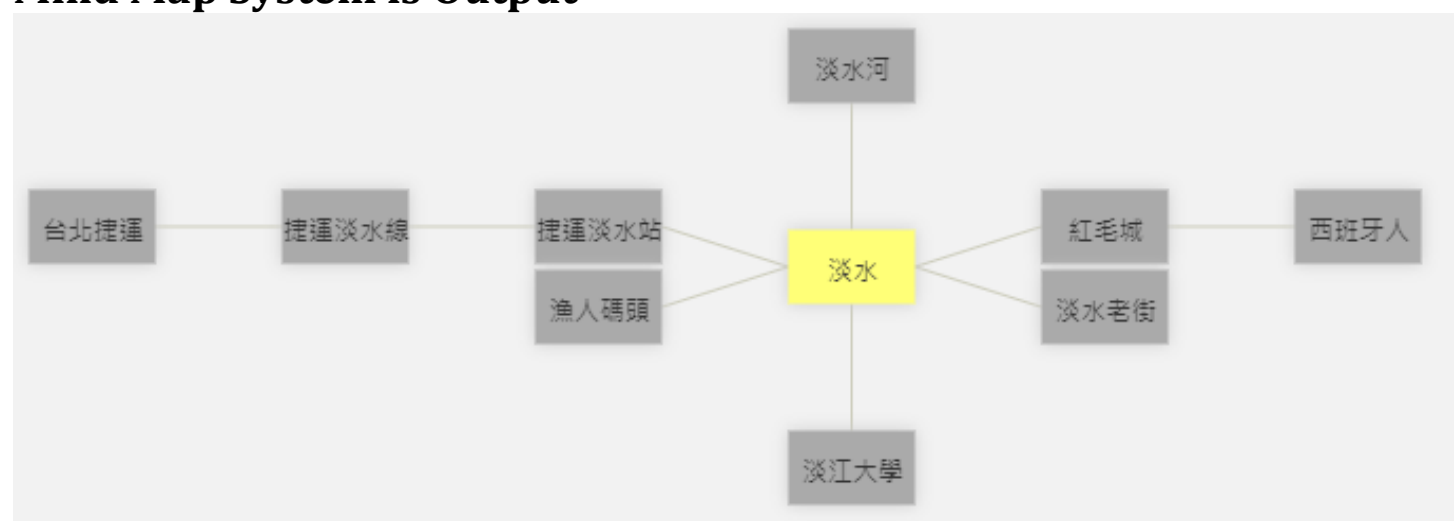

Athabasca

University

(c) (†) 